\title{
Phenotypic correction and stable expression of factor VIII in hemophilia A mice by embryonic stem cell therapy
}

\author{
J.J. Wang ${ }^{1 *}$, Y. Kuang ${ }^{2 *}$, L.L. Zhang ${ }^{3}$, C.L. Shen ${ }^{3}$, L. Wang ${ }^{4}$, S.Y. Lu ${ }^{4}$, \\ X.B. $\mathrm{Lu}^{2}$, J. Fei ${ }^{2}$, M.M. Gu ${ }^{1}$ and Z.G. Wang ${ }^{1-4}$ \\ ${ }^{1}$ Model Organism Division, Department of Medical Genetics, \\ E-Institutes of Shanghai Universities, \\ Shanghai Jiao Tong University School of Medicine, Shanghai, China \\ ${ }^{2}$ Shanghai Research Center for Model Organisms, Shanghai, China \\ ${ }^{3}$ Institute of Health Sciences, \\ Shanghai Institutes for Biological Sciences of Chinese Academy of Sciences, \\ Shanghai Jiao Tong University School of Medicine, Shanghai, China \\ ${ }^{4}$ State Key Laboratory of Medical Genomics, \\ Shanghai Institute of Hematology, \\ Rui-Jin Hospital Affiliated to Shanghai Jiao Tong University School of Medicine, \\ Shanghai, China
}

*These authors contributed equally to this study.

Corresponding author: Z.G. Wang

E-mail: zhugangw@shsmu.edu.cn

Genet. Mol. Res. 12 (2): 1511-1521 (2013)

Received March 28, 2012

Accepted November 23, 2012

Published May 13, 2013

DOI http://dx.doi.org/10.4238/2013.May.13.4

\begin{abstract}
Hereditary deficiency of factor VIII (FVIII) leads to hemophilia A, a severe X-linked bleeding disorder. Current therapies include fixed-dose FVIII prophylaxis, factor replacement therapy, and most recently, gene therapy. Prophylaxis and FVIII replacement therapies are limited by incomplete efficacy, high cost, restricted availability, and development of neutralizing antibodies in chronically
\end{abstract}


treated individuals. Limited success has been obtained in preclinical trials using gene therapy for the treatment of hemophilia. Therefore, new options for therapy for hemophilia A are needed. We evaluated the potential of embryonic stem cells for correcting hemophilia A in mice. FVIII-deficient mouse blastocysts were collected and injected with mouse embryonic stem cells stably expressing green-fluorescent protein (GFP) and transferred to pseudopregnant recipient mice. Expression of FVIII was measured in the liver and plasma of the 5 chimeric mice that were produced. Three of these mice were GFPpositive at the age of 6 months. The plasma FVIII activity levels were equal to those of wild-type mice. These data demonstrate that embryonic stem cell transplantation at an early embryonic stage has potential as therapy for this progressively debilitating, lifethreatening bleeding disorder.

Key words: Hemophilia A; FVIII; Embryonic stem cells; Blastocysts; Chimeric mice

\section{INTRODUCTION}

Hemophilia $\mathrm{A}$ is a severe inherited $\mathrm{X}$-linked bleeding disorder caused by quantitative or qualitative deficiency of coagulation factor VIII (FVIII). Hemophilia A occurs in 1-2 individuals per 10,000 and represents roughly $90 \%$ of hemophilia cases (Fakharzadeh et al., 2000; Xu et al., 2009). Clinically, the disease is characterized by spontaneous bleeding into the large joints and soft tissues. Recurrent episodes of joint bleeding are the most frequent symptom of the disease, leading to crippling arthropathy, particularly in severely affected patients. Currently, the most widely accepted treatment for hemorrhagic episodes is intravenous (iv) administration of plasma-derived FVIII concentrates or the recombinant FVIII protein. However, the high cost and unpredictable shortages of recombinant FVIII and risk of transmission of blood-borne viruses (historically, hepatitis A, B, and C, HIV, and B19 parvovirus) with plasma-derived FVIII have propelled researchers to look for alternative approaches (Moayeri et al., 2005). Gene therapy of hemophilia has been initiated through a number of approaches including expression in muscle-, liver-, and omental-implanted fibroblasts, or $i v$ injection of an expression vector under the control of a ubiquitous promoter (Montgomery et al., 2010).

Limited success has been reported in preclinical trials using gene therapy for the treatment of hemophilia (Balague et al., 2000; Guo et al., 2001; Kootstra et al., 2003; Saenko et al., 2003; Tiede et al., 2003; Ye et al., 2004; Moayeri et al., 2005; Hauck et al., 2006; Ide et al., 2007; Matsui et al., 2007; Xu et al., 2005, 2007). Treatment failure is primarily caused by host immune responses to virally encoded proteins and lack of sustained production of the therapeutic gene products.

Embryonic stem (ES) cells can differentiate into most cell types, thus leading to intense interest in their potential for therapeutic applications (Hwang et al., 2004). Our intent in this study was to evaluate the therapeutic application of ES cells for treatment of a preclinical mouse model of hemophilia A. Our results showed total correction of hemophilia A mice by in vivo ES cell therapy. 


\section{MATERIAL AND METHODS}

\section{Mice}

FVIII-deficient (FVIII ${ }^{\text {null }}$ ) mice have been previously described (Kuang et al., 2010). Briefly, exons 16-19 of FVIII were deleted. Polymerase chain reaction (PCR), reverse-transcription (RT)-PCR, and immunohistochemistry confirmed FVIII deficiency in the FVIII gene knockout mouse. FVIII activity of FVIII ${ }^{\text {null }}$ mice was remarkably lower than in normal mice. Since, the FVIII ${ }^{\text {null }}$ mouse has significant, and even lethal, bleeding after trauma of tail snip, its phenotype appears grossly similar to that of humans with severe hemophilia A. The mutant mice were kept on an inbred 129S3 background under specific pathogen-free conditions. The protocols used in this study were approved by the Animal Use and Care Committee of Shanghai Jiao Tong University School of Medicine.

\section{Cell culture}

ES cells (from strain 129S3 mice) and stable green-fluorescent protein (GFP)-ES cell lines (transfected with pEGFP-N2) were grown and maintained undifferentiated at $37^{\circ} \mathrm{C}$ in $5 \% \mathrm{CO}_{2}$ on mitomycin C-treated mouse embryonic fibroblast feeder cells. ES and GFP-ES cells were cultured in KO-DMEM medium (Invitrogen, Carlsbad, CA, USA) plus 15\% ES cell-grade FBS (Invitrogen), $0.1 \mathrm{mM}$ non-essential amino acids, $2 \mathrm{mM}$ L-glutamine, $0.1 \mathrm{mM}$ 2-mercaptoethanol, $50 \mathrm{U} / \mathrm{mL}$ penicillin, $50 \mu \mathrm{g} / \mathrm{mL}$ streptomycin, $1 \mathrm{mM}$ sodium pyruvate, and $1000 \mathrm{U} / \mathrm{mL}$ leukemia-inhibitory factor (Invitrogen).

\section{Production of chimeric mice and experimental groups}

Female FVIII ${ }^{\text {null }}$ mice were superovulated with pregnant mare serum gonadotrophin and human chorionic gonadotrophin and mated to FVIII ${ }^{\text {null }}$ male mice. In total, 65 blastocysts were isolated at day 3.5 postcoitum from females with a vaginal plug. The collected blastocysts were randomly divided into 2 groups: treatment group - 35 blastocysts were injected with GFP-ES cells and transferred to pseudopregnant recipient females; control group - 30 blastocysts were directly transferred to pseudopregnant recipient females. The pups were checked under a fluorescence-dissecting microscope for GFP expression 3 days after birth. Three of 5 pups derived from the injected blastocysts were GFP-positive. Four pups were born in the control group.

\section{PCR analysis}

Genomic DNA was extracted from the livers of chimeras and control mice at the age of 6 months. The FVIII and GFP genomic sequences were detected by using the following primers: FVIII: 5'-CACTTGTAAGAGTTTGGGGATG-3' (forward) and 5'-GTAATCTGGAAATCAC GGATGC-3' (reverse); GFP: 5'-CTGGTCGAGCTGGACGGCGACG-3' (forward) and 5'-CACGAACTCCAGCAGGACCATG-3' (reverse), respectively. All samples were also amplified to detect $\beta$-actin (forward primer: 5'-TACCCAGGCATTGCTGACAGG-3'; reverse primer: 5'-ACTTGCGGTGCACGATGGA-3') as a control for the presence of amplifiable DNA. PCR products were analyzed by agarose gel electrophoresis and ethidium bromide staining. 


\section{RNA extraction and RT-PCR}

Total RNA was extracted from cultured ES cells or mouse tissues with Trizol reagent (Invitrogen). Total RNA ( $2 \mu \mathrm{g})$ was reverse-transcribed, and PCR was done with ExTaq (Takara, Dalian, China). The primers used in this study are listed in Table 1.

\begin{tabular}{|c|c|}
\hline Gene symbol & Primer sequence $\left(5^{\prime} \rightarrow 3^{\prime}\right)$ \\
\hline \multirow[t]{2}{*}{$\overline{\text { Nanog }}$} & F: 5'-CAGGTGTTTGAGGGTAGCTC-3' \\
\hline & R: 5'-CGGTTCATCATGGTACAGTC-3' \\
\hline \multirow{2}{*}{ Eras } & F: 5'-ACTGCCCCTCATCAGACTGCTACT-3' \\
\hline & R: 5'-CACTGCCTTGTACTCGGGTAGCTG-3' \\
\hline \multirow{2}{*}{ Fgf4 } & F: 5'-CGTGGTGAGCATCTTCGGAGTGG-3' \\
\hline & R: 5'-CCTTCTTGGTCCGCCCGTTCTTA-3' \\
\hline \multirow{2}{*}{ Oct $3 / 4$} & F: 5'-TCTTTCCACCAGGCCCCCGGCTC-3' \\
\hline & R: 5'-TGCGGGCGGACATGGGGAGATCC-3' \\
\hline \multirow{2}{*}{ Cripto } & F: 5'-ATGGACGCAACTGTGAACATGATGTTCGCA-3' \\
\hline & R: 5'-CTTTGAGGTCCTGGTCCATCACGTGACCAT-3' \\
\hline \multirow[t]{2}{*}{ Dax1 } & F: 5'-TGCTGCGGTCCAGGCCATCAAGAG-3' \\
\hline & R: 5'-GGGCACTGTTCAGTTCAGCGGATC-3' \\
\hline \multirow[t]{2}{*}{ Sox 2} & F: 5'-TAGAGCTAGACTCCGGGCGATGA-3' \\
\hline & R: 5'-TTGCCTTAAACAAGACCACGAAA-3' \\
\hline \multirow[t]{2}{*}{ GFP } & F: 5'-CTGGTCGAGCTGGACGGCGACG-3' \\
\hline & R: 5'-CACGAACTCCAGCAGGACCATG-3' \\
\hline \multirow[t]{2}{*}{ FVIII } & F: 5'-TCGTGGAGAATTAAATGAACA-3' \\
\hline & R: 5'-CGAGCACCCTGAGTCTTGATG-3' \\
\hline \multirow{2}{*}{$\beta$-actin } & F: 5'-TACCCAGGCATTGCTGACAGG-3' \\
\hline & R: 5'-ACTTGCGGTGCACGATGGA-3' \\
\hline
\end{tabular}

\section{Alkaline phosphatase (ALP) staining}

ES and GFP-ES cells were stained for ALP activity according to manufacturer instructions using the Alkaline Phosphatase Detection kit (Millipore, Billerica, MA, USA).

\section{Factor VIII activity}

A volume of $500 \mu \mathrm{L}$ citrated test plasma was sent to Ruijin Hospital (Shanghai, China) for detection of FVIII activity using the chromogenic FVIII activity assay according to manufacturer instructions. A standard curve was created by using serial dilutions of normal human reference plasma. For plasma isolation, mice were anesthetized with ketamine/xylazine, and $1 \mathrm{~mL}$ blood was obtained by removing the eyeball and collected in $0.16 \mathrm{M}$ sodium citrate at a final ratio of 1:10 (anticoagulant/blood).

\section{Immunohistochemistry}

Livers were removed and frozen in Tissue-Tek OCT compound (Sakura Finetechnical, Tokyo, Japan), and sections were cut at $8 \mu \mathrm{m}$ thickness. Sections were air-dried for $30 \mathrm{~min}$ and fixed in 4\% paraformaldehyde for 10 min. For staining, sections were covered with 1:100 anti-FVIII antibody (Santa Cruz, Santa Cruz, CA, USA) solution and incubated overnight at $4^{\circ} \mathrm{C}$. After washing, the sections were incubated with goat anti-rabbit antibody (KPL, Gaith- 
ersburg, MD, USA) for $1 \mathrm{~h}$ at $37^{\circ} \mathrm{C}$. After another wash, the sections were developed using the ABC kit (Vector Labs, Burlingame, CA, USA). The slides were then mounted in DPX (Sigma, St. Louis, MO, USA) and examined under a microscope with a $40 \mathrm{X}$ objective.

\section{Statistical analysis}

The results are reported as means \pm standard error. The Student $t$-test was used for comparisons between groups. P less than 0.05 was considered to be statistically significant.

\section{RESULTS}

\section{Characterization of GFP-ES cells}

To confirm that the undifferentiated status of GFP-ES cells had not changed during the process of generating stable cell lines, we first examined the morphology and ALP activity of GFP-ES cells. It was found that GFP-ES cells were morphologically similar to ES cells including a round shape, large nucleoli, and scant cytoplasm (Figure 1A). Both ES and GFP-ES cell clones stained positive for ALP (Figure 1B). We further characterized GFP-ES cells at the molecular level by examining the expression of ES cell-specific markers. RT-PCR analyses showed that they expressed ES cell markers, including Nanog, Eras, Dax1, Oct3/4, Cripto, Fgf4, and Sox2, in quantities similar to those in ES cells (Figure 1C).

A

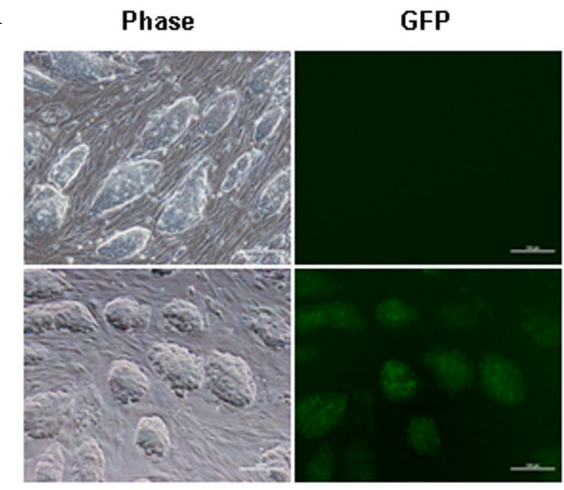

B

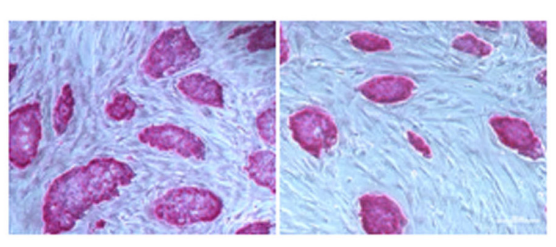

C

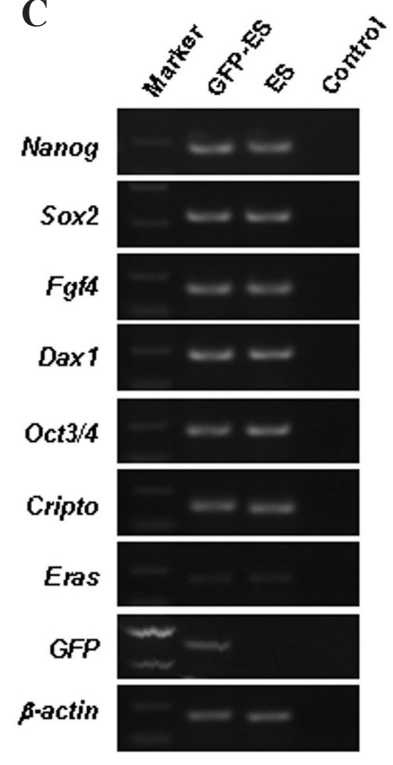

Figure 1. Characterization of GFP-ES cells. A. Morphology of embryonic stem (ES) (top) and green-fluorescent protein (GFP)-ES (bottom) cells was analyzed with a fluorescence microscope. Scale bar $=100 \mu \mathrm{m}$. B. Alkaline phosphatase staining of ES (left) and GFP-ES (right) cells. Scale bar $=100 \mu \mathrm{m}$. C. RT-PCR analysis of ES cell markers in ES cells and GFP-ES cells. $\beta$-actin was used as a loading control. 


\section{GFP expression in chimeric mice}

We obtained 65 blastocysts from female FVIII ${ }^{\text {null }}$ mice, and they were randomly divided into 2 parts: 35 of them were injected with GFP-ES cells and then implanted into 3 pseudopregnant recipient females; the remaining blastocysts were directly implanted into 3 pseudopregnant recipient females. After 18 days, 5 chimeric mice and 4 FVIII ${ }^{\text {null }}$ mice were born. We used a fluorescence dissecting microscope to check whether GFP was expressed in pups 3 days after birth. GFP was easily visualized in 3 chimeric mice (chimeras ${ }^{\mathrm{gfp}+}$ ), but not visualized in the other 2 chimeric mice (chimeras ${ }^{\mathrm{gtp}-}$ ) (Figure 2).

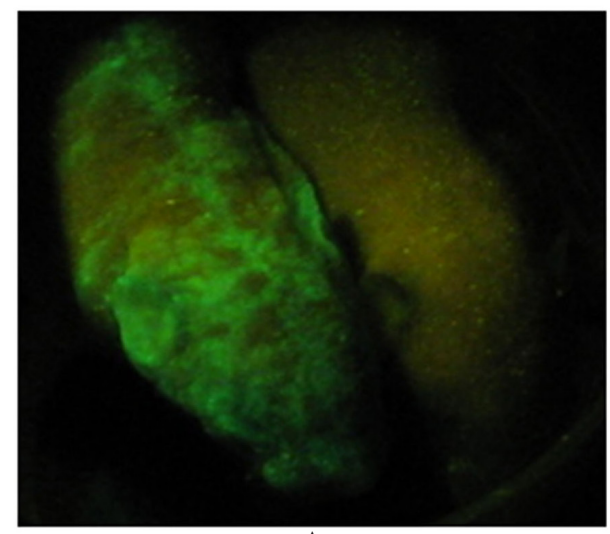

A

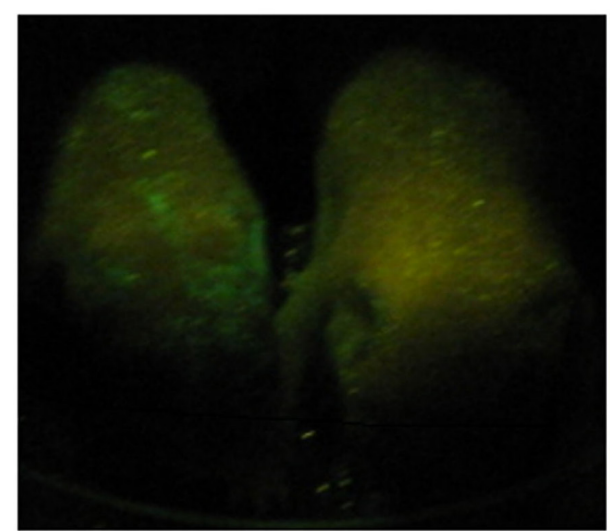

C

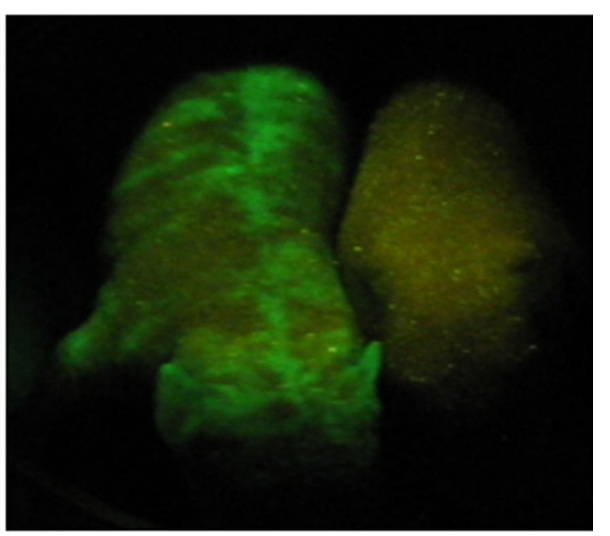

B

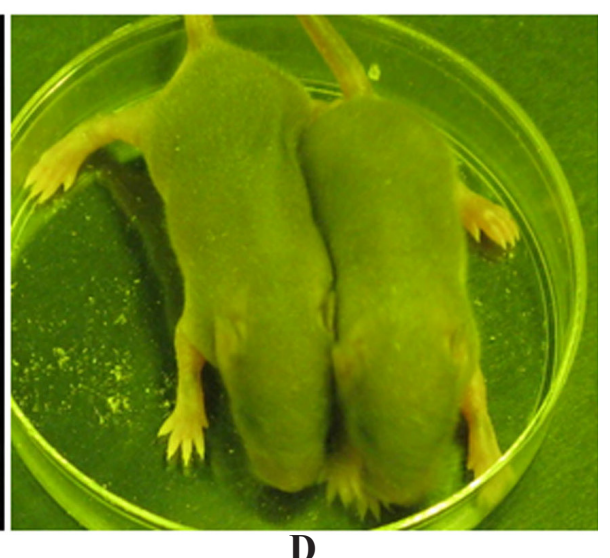

D

Figure 2. Bright-field and fluorescence images of mice (3 days). A. and B. Chimeric mice. C. Chimeric mice (left), FVIII $^{\text {null }}$ mice (right). D. Bright-field image of chimeric mice (left) and FVIII ${ }^{\text {null }}$ mice (right).

\section{FVIII expression in chimeric mice}

The chimeric mice were viable and reached the adult stage without any gross morphological abnormalities. Six months later, the presence of FVIII and GFP sequences 
was demonstrated by genomic PCR in 3 of 5 chimeric livers (Figure 3A). Similarly, RTPCR analyses showed that both FVIII and GFP were expressed in 3 of 5 chimeric livers. As the controls, FVIII mRNA from wide-type (1023 bp) and targeted alleles (284 bp) were detected in wide-type mice, and all chimeras and FVIII ${ }^{\text {null }}$ controls, respectively (Figure 3B).

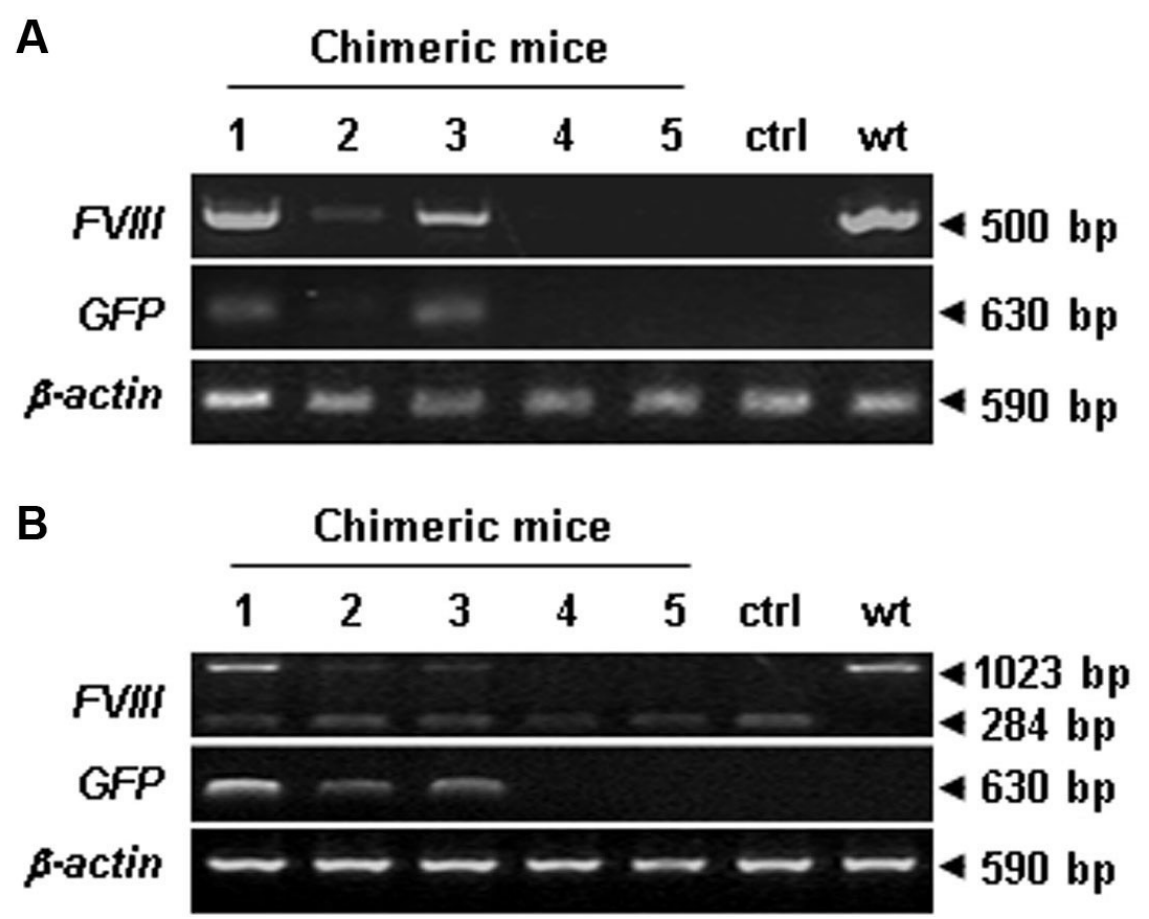

Figure 3. FVIII expression in chimeric mice. A. PCR analysis using genomic DNA extracted from liver tissues shows that FVIII and green-fluorescent protein (GFP) sequences were detected in chimeras ${ }^{\text {gfp }}{ }^{\text {mice. }} \beta$-actin was used as a loading control. Lanes $1-3=$ chimeras $^{\text {gfp }}$; lanes 4 and $5=$ chimeras $^{\text {gfp- }}$; lane $c t r l=$ control FVIII $^{\text {null }}$ mice. B. RT-PCR analysis shows that FVIII and GFP were expressed in chimeras ${ }^{\mathrm{fp}+}$. $\beta$-actin was used as a loading control. Lanes $1-3=$ chimeras $^{\text {gfp }}$; lanes 4 and $5=$ chimeras $^{\text {gfp- }}$; lane $c t r l=$ control FVIII ${ }^{\text {null }}$ mice. Total RNA was extracted from livers. $\mathrm{wt}=$ wild-type mice.

All groups of mice were tested for FVIII activity. It was observed that the plasma FVIII:C levels in chimeras ${ }^{\mathrm{gfp}+}$ were similar to those in wild-type control mice, but remarkably higher than those in FVIII ${ }^{\text {null }}$ mice. The plasma FVIII:C levels in chimeras ${ }^{\text {gfp- }}$ were not significantly different from those in FVIII ${ }^{\text {null }}$ mice (Figure 4).

Finally, we examined the expression and distribution of FVIII in the livers by immunohistochemical staining. The results showed that the FVIII protein was detectable in the chimeras ${ }^{\mathrm{gfp}}{ }^{+}$but not in FVIII ${ }^{\text {null }}$ livers, and FVIII expression was noted in hepatocytes (Figure 5). These data reveal that ES cells transplanted into mouse embryos differentiated to FVIII-producing hepatocytes, leading to complete correction of the hemophilia A mouse phenotype. 


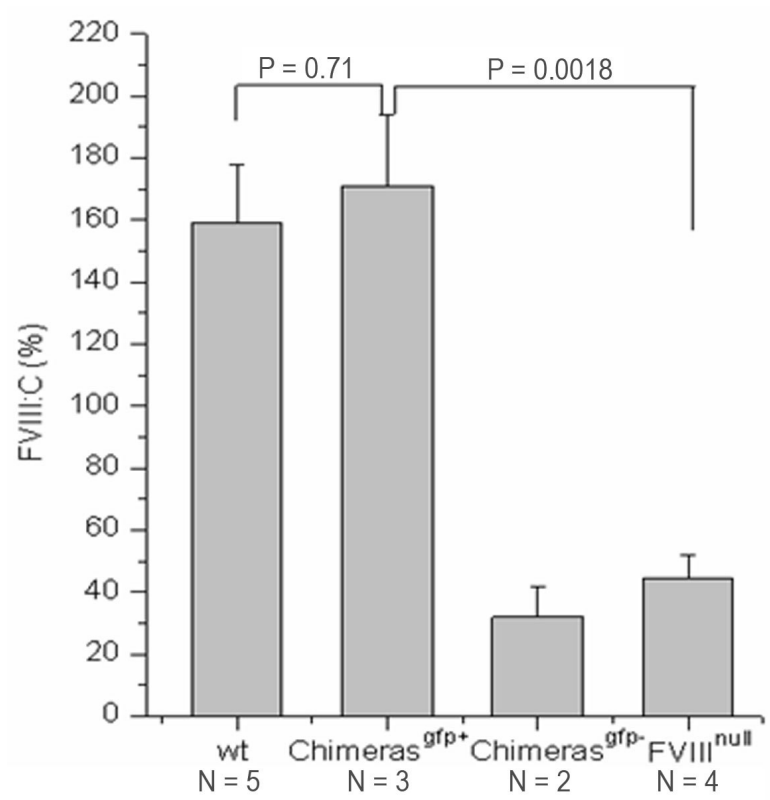

Figure 4. Quantitative evaluation of FVIII activity levels in mouse plasma. FVIII:C was detected in the plasma of chimeric mice. The level of FVIII:C in chimeras ${ }^{\mathrm{gfp}+}$ was similar to wild-type (wt) mice.

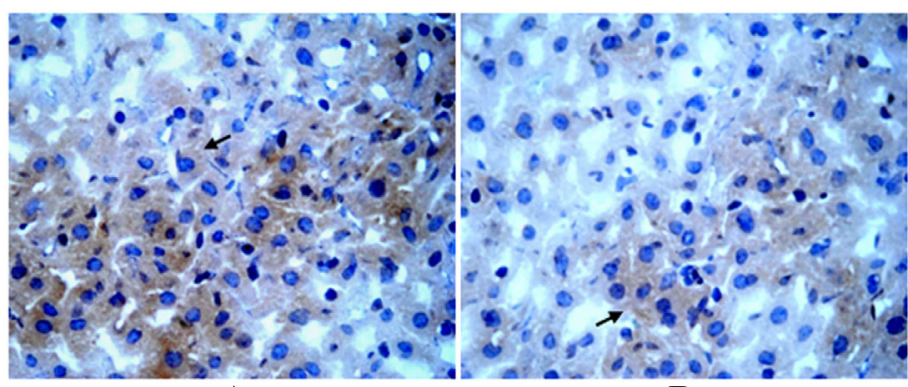

A

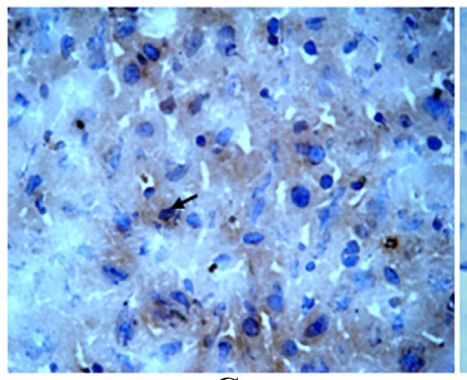

C
B.

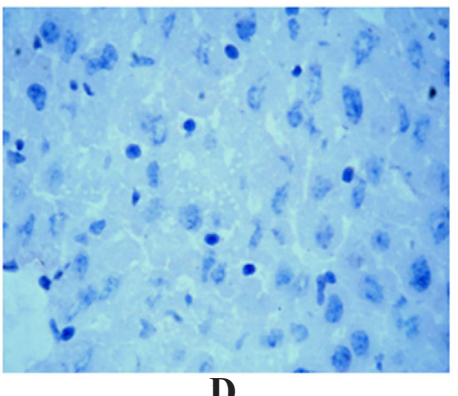

D

Figure 5. FVIII was detectable in chimeric liver by immunohistochemistry staining. The FVIII protein was detected in livers of chimeras ${ }^{\text {gfp }}(\mathbf{A}-\mathbf{C})$ but not in FVIII ${ }^{\text {null }}$ mouse liver (D). Arrows point to examples of positive cells. Sections are viewed under 400X magnification. 


\section{DISCUSSION}

Hemophilia A is a rare X-linked bleeding disorder caused by the lack or dysfunction of coagulation FVIII (Yatuv et al., 2010). Replacement therapy may be supplied on-demand (to stop a bleed) or prophylactically (to prevent bleeds). When treatment is provided on-demand, injections must be initiated at the first onset of symptoms so as to restrict both the amount of bleeding and the extent of the resulting tissue damage. Prophylactic therapy has been shown to provide hemophilia patients with better full-scale care than on-demand treatment, as it reduces the frequency of hemorrhages and retards the development of long-term arthropathy (Hoots and Nugent, 2006). However, prophylactic treatment is more expensive than on-demand treatment and is not suitable for many patients. With either approach, neutralizing antibodies to the replacement protein have been reported, presenting a unique problem when treating hemophilia patients (Kaufman, 1999; Scandella, 2000).

Gene therapy has long been recognized as a desirable treatment for hemophilia A, since it is caused by mutations in a single verified gene, and because a slight increase in clotting factor levels in vivo can convert severe hemophilia into a milder disease (Kessler, 2005). However, all clinical trials for gene therapy in hemophilia A have been interrupted because of complications and failure to achieve significant FVIII expression in humans with hemophilia A (Pierce et al., 2007).

A chimera is an animal that contains at least 2 different populations of genetically distinct cells. Chimeras are representatively seen in non-human zoology, but are also discovered to a rare extent in humans. Chimeric mice are vital tools in biological research, as they allow the study of a variety of biological questions in an animal that has 2 distinct genetic pools within it, which include insights into such problems as the tissue specific requirements of a gene, and cell lineage. The general methods for generating chimeric mice can be summarized as involving either injection or the aggregation of embryonic cells from different origins. The first chimeric mouse was created by Beatrice Mintz in the 1960s through the aggregation of 8-cell stage embryos (Mintz and Silvers, 1967). Injection on the other hand was pioneered by Richard Gardner and Ralph Brinster who injected cells into blastocysts to generate chimeric mice with germ lines completely derived from injected ES cells (Robertson et al., 1983). ES cells are also an important tool in chimeras because genes can be mutated in them through the use of homologous recombination, thus allowing gene targeting. Since this discovery took place in 1999, ES cells have become a key tool in the generation of specific chimeric mice (Doetschman et al., 1988).

In the current study, the chimeric mice described as chimeras ${ }^{\mathrm{gfp}+}$ have 3 features that make them highly promising in the future. First, chimeras ${ }^{\mathrm{gfp}+}$ are made through injection of the GFP-ES cells into the diploid embryo. Second, chimeras ${ }^{\mathrm{gfp}+}$ are phenotypic correction of bleeding disorder. Third, FVIII has a short half-life requiring continuous replacement, but the FVIII protein is stably expressed in chimeras ${ }^{\mathrm{gpp}^{\mathrm{p}}}$.

In this study, some questions require further investigation. For example, long-term follow-up throughout their lifetimes will be needed to determine whether downstream adverse effects will emerge in the mice, and other stem cells need to be found to substitute ES cell. Ideally, one would like to use induced pluripotent stem (iPS) cells from patient's somatic cells, and these iPS cells need some genetic modifications. To date, iPS cells appear to be indistinguishable from ES cells and thus provide tremendous therapeutic potential (Hanna et 
al., 2007; Lewitzky and Yamanaka, 2007; Okita et al., 2007; Takahashi et al., 2007; Yu et al., 2007; Park et al., 2008). Our results open the way to further investigations aimed at extending cell therapy for hemophilia A.

We demonstrated that ES cell transplantation at an early embryonic stage could rescue the hemophilia A phenotype in mice. This strategy, especially by using iPS, may be a potential therapy in the future for this progressively debilitating, life-threatening bleeding disorder.

\section{ACKNOWLEDGMENTS}

Research supported in part by the National Natural Science Foundation of China (\#30530390,\#30871420), the Ministry of Science and Technology of China (\#2006BAI23B02, \#2011BA115B02), the Science and Technology Commission of Shanghai Municipality (\#10DZ2251500, \#10140901400), the National Comprehensive Technology Platforms for Innovative Drug R\&D Program (\#2009ZX09301-007), and E-Institutes of Shanghai Municipal Education Commission (\#E03003).

\section{REFERENCES}

Balague C, Zhou J, Dai Y, Alemany R, et al. (2000). Sustained high-level expression of full-length human factor VIII and restoration of clotting activity in hemophilic mice using a minimal adenovirus vector. Blood 95: 820-828.

Doetschman T, Maeda N and Smithies O (1988). Targeted mutation of the Hprt gene in mouse embryonic stem cells. Proc. Natl. Acad. Sci. U. S. A. 85: 8583-8587.

Fakharzadeh SS, Zhang Y, Sarkar R and Kazazian HH Jr (2000). Correction of the coagulation defect in hemophilia A mice through factor VIII expression in skin. Blood 95: 2799-2805.

Guo X, Wang H, Chu H, Wang X, et al. (2001). High level expression of human factor VIII in mammalian cells after retroviral-mediated gene transfer. Chin. Med. J. 114: 690-693.

Hanna J, Wernig M, Markoulaki S, Sun CW, et al. (2007). Treatment of sickle cell anemia mouse model with iPS cells generated from autologous skin. Science 318: 1920-1923.

Hauck B, Xu RR, Xie J, Wu W, et al. (2006). Efficient AAV1-AAV2 hybrid vector for gene therapy of hemophilia. Hum. Gene Ther. 17: 46-54.

Hoots WK and Nugent DJ (2006). Evidence for the benefits of prophylaxis in the management of hemophilia A. Thromb. Haemost. 96: 433-440.

Hwang WS, Ryu YJ, Park JH, Park ES, et al. (2004). Evidence of a pluripotent human embryonic stem cell line derived from a cloned blastocyst. Science 303: 1669-1674.

Ide LM, Gangadharan B, Chiang KY, Doering CB, et al. (2007). Hematopoietic stem-cell gene therapy of hemophilia A incorporating a porcine factor VIII transgene and nonmyeloablative conditioning regimens. Blood 110: 2855-2863.

Kaufman RJ (1999). Advances toward gene therapy for hemophilia at the millennium. Hum. Gene Ther. 10: 2091-2107.

Kessler CM (2005). New perspectives in hemophilia treatment. Hematology Am. Soc. Hematol. Educ. Program 429-435.

Kootstra NA, Matsumura R and Verma IM (2003). Efficient production of human FVIII in hemophilic mice using lentiviral vectors. Mol. Ther. 7: 623-631.

Kuang Y, Wang J, Lu X, Lu S, et al. (2010). Generation of factor VIII gene knockout mouse by tetraploid embryo complementation technology. Zhonghua Yi. Xue. Yi. Chuan Xue. Za Zhi. 27: 1-6.

Lewitzky M and Yamanaka S (2007). Reprogramming somatic cells towards pluripotency by defined factors. Curr. Opin. Biotechnol. 18: 467-473.

Matsui H, Shibata M, Brown B, Labelle A, et al. (2007). Ex vivo gene therapy for hemophilia A that enhances safe delivery and sustained in vivo factor VIII expression from lentivirally engineered endothelial progenitors. Stem. Cells 25: 2660-2669.

Mintz B and Silvers WK (1967). "Intrinsic" immunological tolerance in allophenic mice. Science 158: 1484-1486.

Moayeri M, Hawley TS and Hawley RG (2005). Correction of murine hemophilia A by hematopoietic stem cell gene therapy. Mol. Ther. 12: 1034-1042.

Montgomery RR, Monahan PE and Ozelo MC (2010). Unique strategies for therapeutic gene transfer in haemophilia A and haemophilia BWFH State-of-the-Art Session on Therapeutic Gene Transfer Buenos Aires, Argentina. Haemophilia 
(Suppl 16) 5: 29-34.

Okita K, Ichisaka T and Yamanaka S (2007). Generation of germline-competent induced pluripotent stem cells. Nature 448: 313-317.

Park IH, Zhao R, West JA, Yabuuchi A, et al. (2008). Reprogramming of human somatic cells to pluripotency with defined factors. Nature 451: 141-146.

Pierce GF, Lillicrap D, Pipe SW and Vandendriessche T (2007). Gene therapy, bioengineered clotting factors and novel technologies for hemophilia treatment. J. Thromb. Haemost. 5: 901-906.

Robertson EJ, Evans MJ and Kaufman MH (1983). X-chromosome instability in pluripotential stem cell lines derived from parthenogenetic embryos. J. Embryol. Exp. Morphol. 74: 297-309.

Saenko EL, Ananyeva NM, Moayeri M, Ramezani A, et al. (2003). Development of improved factor VIII molecules and new gene transfer approaches for hemophilia A. Curr. Gene Ther. 3: 27-41.

Scandella DH (2000). Properties of anti-factor VIII inhibitor antibodies in hemophilia A patients. Semin. Thromb. Hemost. 26: $137-142$.

Takahashi K, Tanabe K, Ohnuki M, Narita M, et al. (2007). Induction of pluripotent stem cells from adult human fibroblasts by defined factors. Cell 131: 861-872.

Tiede A, Eder M, von Depka M, Battmer K, et al. (2003). Recombinant factor VIII expression in hematopoietic cells following lentiviral transduction. Gene Ther. 10: 1917-1925.

Xu D, Alipio Z, Fink LM, Adcock DM, et al. (2009). Phenotypic correction of murine hemophilia A using an iPS cellbased therapy. Proc. Natl. Acad. Sci. U. S. A. 106: 808-813.

Xu L, Nichols TC, Sarkar R, McCorquodale S, et al. (2005). Absence of a desmopressin response after therapeutic expression of factor VIII in hemophilia A dogs with liver-directed neonatal gene therapy. Proc. Natl. Acad. Sci. U. S. A. 102: 6080-6085.

Xu L, Mei M, Ma X and Ponder KP (2007). High expression reduces an antibody response after neonatal gene therapy with B domain-deleted human factor VIII in mice. J. Thromb. Haemost. 5: 1805-1812.

Yatuv R, Robinson M, Dayan-Tarshish I and Baru M (2010). The use of PEGylated liposomes in the development of drug delivery applications for the treatment of hemophilia. Int. J. Nanomedicine 5: 581-591.

Ye P, Thompson AR, Sarkar R, Shen Z, et al. (2004). Naked DNA transfer of Factor VIII induced transgene-specific, species-independent immune response in hemophilia A mice. Mol. Ther. 10: 117-126.

Yu J, Vodyanik MA, Smuga-Otto K, Antosiewicz-Bourget J, et al. (2007). Induced pluripotent stem cell lines derived from human somatic cells. Science 318: 1917-1920. 